\title{
Functionality of TV Control Applications
}

\author{
Mariusz Śniadkowski ${ }^{1}$ \\ 1 Faculty of Technology Fundamentals, Lublin University of Technology, ul. Nadbystrzycka 38, 20-618 Lublin, \\ Poland \\ e-mail: m.sniadkowski@pollub.pl
}

\begin{abstract}
The need for remote control of a television is uniform, expressed mainly in the ability to change TV channels, TV settings or use the functions built into the TV set. Remote controls have changed over time to meet users' expectations. The latest technologies make it possible to customize remote controls and configure them according to the user's needs. For the average person not well familiar with technology and applications, choosing the right one for a particular brand of TV is not the easiest thing to do, as the amount available is overwhelming the Google offer. The aim of the study is to analyze, compare and identify the most functional application for controlling modern TV sets based on classic Smart TV and Android TV software. The analysis covers applications available on the Google platform, i.e. the Google Play Store.
\end{abstract}

Keywords: Smart TV, remote control, Android TV, applications

\section{INTRODUCTION}

The first televisions did not have the ability to remotely change channels or control the projected image. The built-in buttons provided them with basic functions. Over the years, the technology for controlling a television set has changed fundamentally. The first remote control that allowed remote control of the receiver was wired and had a limited number of controls. The next was based on a torch and had a limited number of functions to a maximum of four. This was followed by a remote control that communicated with the television set via ultrasound. The next era was that of infrared remote controls, which are still used today and have many options for configuring and controlling receivers, from channels to picture to display management. The development of technology has made it possible to control televisions with mobile devices such as smartphones or tablets using a suitable communication source, WiFi or Bluetooth. Thanks to the application, each user can adjust the remote control, button settings and many other functions to their own needs and requirements. The latest step in the development of TV control is gesture and speech. Nowadays, remote controls are constructed in such a way as to make it possible to per-form all possible actions and functions which a given television set has. Families of re-mote controls are compatible with several models of receivers of one brand since TV sets usually differ in some parameter e.g. screen type, refresh rate, diagonal size or sound system but the main subassemblies and all functions in twin models are the same. Control-ling a TV using a smartphone is done indirectly through applications that are available for devices with Android and iOS in dedicated stores for a given system. To be able to use Bluetooth and the Internet to control your TV, it should be equipped with a smart TV system and have a built-in internet module or Bluetooth module. Communication between the mobile device and the receiver can be carried out using three wireless channels: wireless infrared communications (IrDA), Wi-Fi and Bluetooth. Configuration and use of this type of connection is very simple and intuitive, does 
not require any additional knowledge and works just like a classic remote control. You need to select a device from the list of those available in the application, or if there is no device, using the instructions built into the application, download the binary codes from the remote control and save them by applying an infra-red diode from the remote control to the smartphone. To be able to control the TV using a dedicated app, the devices need to be paired properly so that they do not have any interference when working and communicating with each other. Using LAN or Wi$\mathrm{Fi}$, connect your smartphone and TV to a single network and then connect them together so that they can communicate using a dedicated application. In this case, the TV can be controlled from anywhere as long as the devices are connected to the same network. Communication of devices using Bluetooth is simpler, you connect the receiver to a mobile device, tablet or smartphone, and use the remote control function. Of course, each Bluetooth module has a limited operating range, usually providing bandwidth and reliability at a distance of about 10 meters. The latest premium models from well-known TV manufacturers are equipped with voice control technology - the TV follows voice commands and gestures made by the user with his or her hand. Receivers equipped with this technology have Smart TV software, a microphone and a built-in camera with appropriate software. Speech recognition is activated by pressing the button on the remote control, which sends a signal to the receiver that starts listening and at the same time mutes the sound from the TV for the time of giving commands. With today's televisions, you can play games, browse the web, store, make video calls, write notes and even install external applications from the Google Play Store provided by Google. The processor plays the most important role in televisions and other devices of this type. It determines the smoothness of the use of the TV, is responsible for new technologies and beautifies the displayed picture by boosting colors or high resolution, which improves the detail of the image. Currently quad-core processors with clock speeds well above $1 \mathrm{GHz}$ are used. Thanks to the application of considerable computing power of the processors, it is possible to obtain high resolutions, which improve the detail of the displayed image. HD and Full HD resolution $(1920 \times 1080 \mathrm{px}$.), which is currently used as standard in most TV sets, does not require high computing power. On the other hand, TV sets with
4K Ultra HD (4096×2394 px.) and 8K Full Ultra HD $(8192 \times 4608$ px. $)$ or the latest $16 \mathrm{~K}$ resolution $(16384 \times 9216 \mathrm{px}$.) offered to private users maintain the level of detail and detail to the highest possible degree. As the resolution increases, so does the diagonal size of the TV and the refresh rate thanks to powerful logic processors. Screens reach a size of 100 inches and refresh rates of over $300 \mathrm{~Hz}$, resulting in a much sharper picture, especially during dynamic motion. You can also change the aspect ratio of the displayed picture. Most modern TVs are produced with an aspect ratio of 16:9 and this is the standard in which series and TV programs are usually broadcast. There are also TVs with an aspect ratio of 21:9 (as in cinemas). As the format changes, the picture loses its perfection. The dynamic change of aspect ratio is useful when the displayed picture is not adapted to the chosen device, allowing the TV set to be adjusted to the format of the displayed picture. As a result of using components with high computing power, it is possible to control not only the image resolution or refresh rate, but also the display of a film or 3D series at any time using modern screen and processors. Special active 3D glasses are required. The processor, apart from scaling the image to the appropriate resolution, is responsible for the operation of all the components and functions of the TV set, e.g.: surround sound. The receiver can be directly connected to external speakers in 5.1 or even 7.1 systems, where in cooperation with the processor they will provide sound quality comparable to a cinema hall $[1,2,3]$.

\section{MATERIALS AND METHODS}

There are many applications for controlling TV sets. Choosing the right application to control modern TV sets from leading manufacturers such as LG, Samsung, Sony, Philips, Panasonic, Sharp, Toshiba and Xiaomi takes time. More than 200 programs are available for mobile devices equipped with Android 5.1 Lollipop at least. Configuration and use of such applications is not difficult, as the software is usually adapted to users. In order to analyze the available applications on Google Play, a critical literature analysis and a comparative method were used. The method was used to juxtapose applications and then compare individual functions that may be compatible with TV sets and to select the most functional applications and appropriate ones in terms of the 
possibility of con-figuring functions in the application, their availability, types of communication be-tween devices, etc. [4]. Applications available on the Google Play Store can be divided in terms of various categories, for example: universal, working with a specific brand of TV, free and paid. There are applications that are not suitable for use due to too many advertisements, which makes it very difficult to use the application. It is also possible to come across a program that has not been finished and due to errors contained in the code is unstable, and the operation of such an application is discouraging to use. The version of Android on your mobile device should be as recent as possible but not older than 4.22 Jelly Bean. Most applications require Android version 5.0 Lollipop, or even sometimes 6.0 Marsh-mallow. Applications in the Google Play Store are published and made available by private per-sons, independent companies and manufacturers of a given receiver brand. Some of the applications available in the Google Play Store are underdeveloped, outdated or do not fulfil their main task, which is proper control and cooperation with TV sets of various manufacturers. Therefore, criteria were used to select available applications for analysis [5]:

- updating the application at least once every six months. Apps that have not been updated for at least several months may indicate that the owner has abandoned work on it and that the remote will not be compatible with the new devices that manufacturers re-lease on average every six months;

- apps that have an average rating over the number of downloads greater than or equal to 3.9 and have at least 5,000 app ratings. A low rating may indicate incompatibility with a particular model or models of television sets, incorrect and unstable operation on a mobile device, malfunctioning of features, crashes, bugs and underdevelopment of the app as a whole;

- applications uploaded in the last 6 months and which have more than 100 positive reviews and ratings and the average rating significantly exceeds 4.0. Such an application according to the users' opinion works properly and fulfils its task and purpose;

- applications controlling various types of devices such as air conditioners, projectors and other similar devices, including televisions.

After applying the above criteria, 41 applications that meet their purpose and are suitable for controlling televisions and other devices were qualified for analysis [6].

With the selection criteria applied, applications were analyzed from over 200 available applications. The criteria that were applied to the available applications were:

- at least 5,000 user ratings,

- average application rating of at least 3.9,

- at least one update in the last 180 days.

The only exceptions are new apps that were launched within the last 6 months and had a very good initial prognosis, i.e. the minimum number of ratings was 100 , the average rating was above 4.0 and the last update was within the last 3 months. All applications were carefully analyzed in terms of user comments and manufacturer's description as well as in terms of preview images of the application itself, although not in every case the images represented the actual state and appearance of the software. In terms of functionality, applications of independent manufacturers are dominant, because they are universal and therefore compatible with at least several brands of TVs, and not as in the case of applications of the same manufacturers, which support only one brand of TV sets. For example, a remote called 'Universal TV Remote Control' is able to communicate with a much larger number of different TV brands than an app called 'Mi Remote Controller', which only connects to devices and TV sets from the Xiaomi family. The plus side is that it is able to communicate and control not only with the receiver but different devices from this manufacturer. As a result, the user can use a single smartphone equipped with the application to control the air conditioner, receiver, projector, fans or camera and even lighting in the building. In summary, in terms of functionality, applications that allow you to control not only one brand of receivers, but at least two. The ranking in terms of points received is as follows $[8,9]$ :

- Universal TV remote,

- Mi Remote Controller,

- Zaza remote,

- Yatse Kodi remote control,

- Cetus Play android TV,

- Year remote,

- TV Remote control.

The Google Play Store offers apps for controlling your TV that are free, paid and with the possibility of buying some functions for a certain 


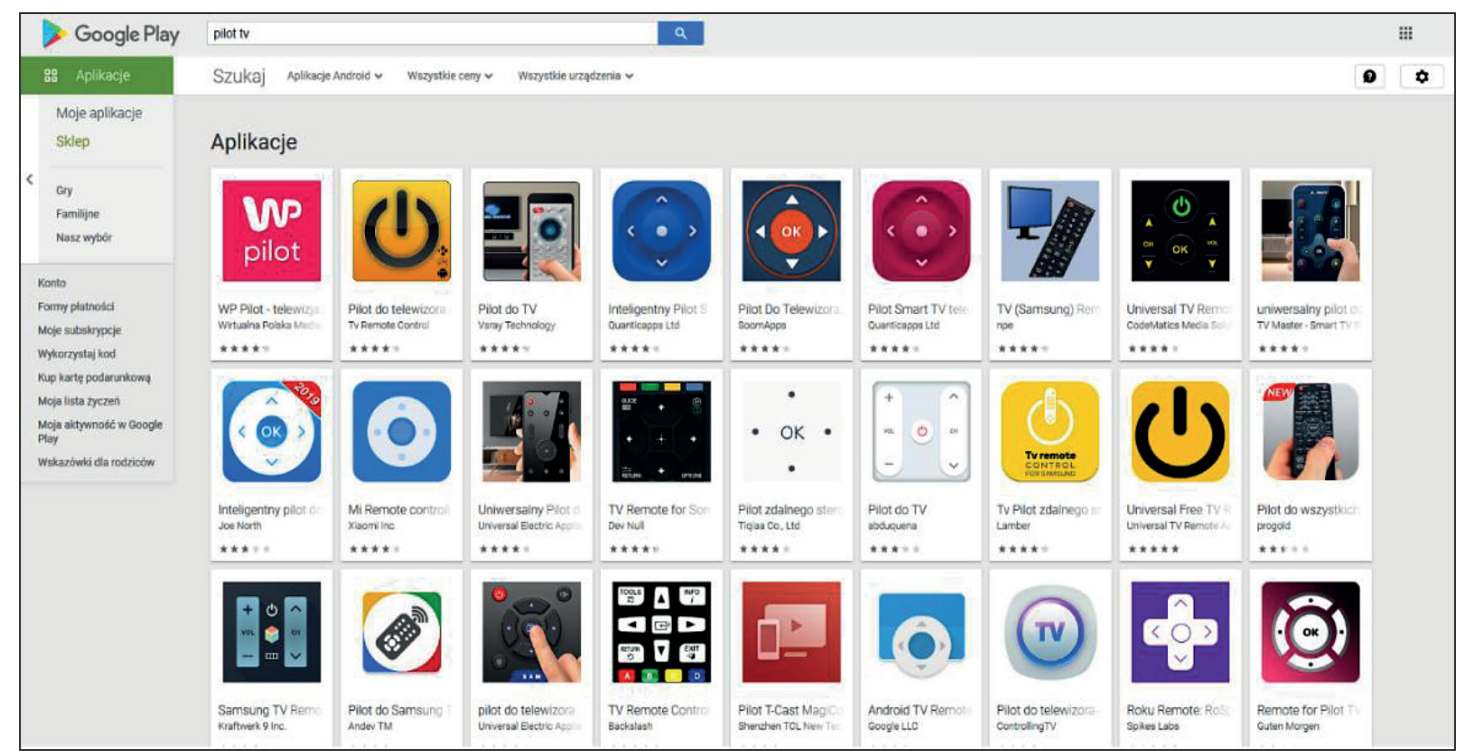

Figure 1. Available applications "pilot tv" in the Google Play Store

amount. Free equivalents usually have one specific button scheme and there is no possibility to configure or change it according to your needs. Free versions can only communicate in one or sometimes two specific ways, while paid versions offer control via all three possibilities: infrared, Bluetooth and using Wi-Fi. They allow you to create shortcuts in the remote control and the possibility of controlling a given application installed on the memory of the TV set without the need to search for a given software in the TV menu. It is also possible to add several different devices or TV sets to an application and, using a drop-down menu, select a given TV and control it without the need for reconfiguration or connection. Thanks to this feature, when several Wi-Fi enabled devices are connected to a local network, a remote control is available for several actions, between which switching takes fractions of a second. Paid applications have the possibility to completely disable advertising, which is a great convenience in using such a remote control. Applications that can be found in the Google Play Store allow you to control your TV using three communication channels: wireless infrared communications IrDA; Bluetooth; Wi-Fi. Some of the applications have the ability to communicate in all three ways but they are paid, free versions have a maximum of two functions of communication with the TV, usually through an infrared diode. The problem is few mobile devices are equipped with $\operatorname{IrDA}$ and especially with Bluetooth and Wi-Fi. All currently produced mobile devices and televisions are equipped with a Bluetooth module at least 4.0 , which is able to provide da-ta transfer rates of up to $40 \mathrm{Mbps}$. Technology is developing and currently the fastest Bluetooth module is 5.0 with a data transfer rate of up to $50 \mathrm{Mbps}$ and with a range of operation of this speed up to $140 \mathrm{~m}$.

\section{RESULTS}

The level of use of the app depends on the user's skills and knowledge of the technology. People who do not have daily contact with the latest technology may have problems with operating the more advanced TV remote controls in the mobile version. Therefore, for such people, the creator of the application should prepare an easy-to-use software or a specially prepared tutorial, which will show step by step how to properly use all the functions of the software, in order to introduce the user to the details. There are applications that do not have any tutorials or introductions, which is an important aspect in the software world. Such apps include those that do not have a lot of features to configure, once they are launched they are ready to go. Remotes dedicated to just one brand of TV are the best, as they have a simple first launch and configuration. The list of applications that are easy to use and do not require additional training, tutorials and received a high number of points:

- TV remote control,

- Remote control for Mi Box, 
- Smart TV remote control for Samsung TVs,

- Remote for Panasonic smart TV,

- Remote control for Ematic JetStream,

- Remote control for android TV,

- Universal remote for all TVs.

Applications to control televisions should ideally communicate using three channels which are IrDA (wireless infrared communications), Bluetooth and Wi-Fi. However, few mobile devices have a built-in infrared diode. Software developers are withdrawing this possibility from their offer, but such devices still exist and applications should have this possibility. Applications that have the ability to communicate with a TV set via an infrared diode and at least one wireless channel are:

- Smart TV remote control for LG TVs,

- Smart TV remote control for Samsung TVs,

- Universal TV remote control,

- Mi remote control,

- Smart TV remote for all,

- TV remote control technology.

Another important factor in choosing an app is the additional costs associated with the software, such as permanent deactivation of ads or the purchase of additional features. The user would like to pay as little as possible to unlock the premium version of a given application. Most applications have a paid version. The list of applications for TV sets, in which the purchase of the entire package does not exceed the value of USD 2.5 - not taking into account discounts, promotional codes, discounts, etc.:

- Philips TV remote,

- Smart TV remote control,

- TCL android TV,

- Remote for LG WebOS,

- Rokie remote for Roku,

- Remote for Panasonic smart TV,

- Sharp TV remote.

However, the premium remotes worthy of recommendation and attention without financial limit are as follows:

- Universal TV remote - charge USD 11.93,

- Universal remote control - lean remote charge USD 8.37,

- Smart TV remote control - charge USD 10.15.

Another important aspect when choosing a remote control is the interface, the ability to work in the background and full screen, the load level of the device. The load measurement was performed with the use of the AIDA64 program for mobile devices. The list of applications with the least load on the device and with the possibility of working in the background is as follows:

- Universal TV remote control,

- Universal LG remote control for smart TV,

- Toshiba TV remote control,

- Vestel remote control.

In addition to the well-known manufacturers of TV sets, there are lesser-known brands such as TCL, Konoka, Skyworth, Hisense or Manta. Not every application offers the possibility of communicating with such devices or does not work properly. List of applications, which are able to communicate with less known brands of TV sets.

- Universal TV remote (premium version),

- TCL android TV,

- Remote for Hisense - year,

- Remote control for SkyQ TV,

- Remote control for Vestel TV.

The following is a list of 41 applications selected from the Google Play Store for analysis in each category and with a rating on a scale from 0 to 5 , the details of which are as follows:

- 0 - no function,

- 1 - available but does not work properly / cannot be used,

- 2 - function available with very limited possibilities,

- 3 - functions available with numerous errors,

- 4 - not all attributes of a function work correctly,

- 5 - the function work correctly.

\section{DISCUSSION}

Applications for controlling TV sets of leading brands can be divided into two groups: paid and free. In both categories, both the free and paid ones take into account proper co-operation with the list of compatible TV sets specified by the software author, have the latest and largest base of supported models and have scored the most points as applications dedicated to a specific TV brand. In the category of premium paid applications, the best remote control application that can be installed on android devices is the "Universal TV remote controller" application. It has a wide base of compatible receivers and devices with 
Table 1. Evaluation of the analyzed applications from the Google Play Store [10, 11]

\begin{tabular}{|c|c|c|c|c|c|c|}
\hline No. & 1 & 2 & 3 & 4 & 5 & 6 \\
\hline Logo/Thumbnail & 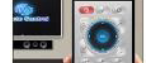 & - > & - > & & $A_{\mathrm{CH}}(1) \mathrm{A}$ & \\
\hline Application name & $\begin{array}{l}\text { TV remote } \\
\text { control }\end{array}$ & $\begin{array}{c}\text { Smart remote } \\
\text { control for } \\
\text { Samsung } \\
\text { Smart TVs }\end{array}$ & $\begin{array}{c}\text { Smart TV } \\
\text { remote } \\
\text { control for LG } \\
\text { TVs }\end{array}$ & $\begin{array}{c}\text { Samsung } \\
\text { TV remote } \\
\text { control }\end{array}$ & $\begin{array}{l}\text { Universal } \\
\text { TV remote } \\
\text { control }\end{array}$ & $\begin{array}{l}\text { Samsung } \\
\text { TV remote } \\
\text { control }\end{array}$ \\
\hline Updates & 2 & 4 & 3 & 4 & 5 & 3 \\
\hline Interaction with the user & 3 & 1 & 2 & 3 & 4 & 1 \\
\hline $\begin{array}{l}\text { Support for more than one brand } \\
\text { of receiver }\end{array}$ & 5 & 0 & 0 & 0 & 5 & 0 \\
\hline Support for additional devices & 0 & 0 & 0 & 0 & 5 & 0 \\
\hline $\begin{array}{l}\text { Possibility to buy a premium } \\
\text { application }\end{array}$ & 0 & 0 & 0 & 0 & 5 & 4 \\
\hline $\begin{array}{l}\text { Possibility to buy individual } \\
\text { functions }\end{array}$ & 3 & 0 & 0 & 2 & 3 & 3 \\
\hline Infrared communication & 0 & 5 & 5 & 0 & 5 & 5 \\
\hline Bluetooth communication & 5 & 5 & 5 & 5 & 5 & 0 \\
\hline Wi-Fi communication & 5 & 5 & 5 & 5 & 5 & 5 \\
\hline Configurable remote control & 3 & 3 & 2 & 3 & 5 & 2 \\
\hline Number of available languages & 2 & 5 & 5 & 2 & 5 & 3 \\
\hline Ability to stream & 0 & 2 & 3 & 0 & 5 & 1 \\
\hline $\begin{array}{l}\text { Supports more than one device } \\
\text { at a time }\end{array}$ & 0 & 0 & 0 & 0 & 3 & 0 \\
\hline Dedicated to one brand only & 0 & 5 & 5 & 5 & 0 & 5 \\
\hline Interface configuration & 3 & 3 & 4 & 2 & 5 & 2 \\
\hline Easy to use & 5 & 5 & 3 & 3 & 4 & 3 \\
\hline Total & 36 & 43 & 42 & 34 & 69 & 37 \\
\hline
\end{tabular}

\begin{tabular}{|c|c|c|c|c|c|c|}
\hline No. & 7 & 8 & 9 & 10 & 11 & 12 \\
\hline Logo/Thumbnail & & $\begin{array}{c}\bullet \\
\bullet \quad \mathrm{OK} ・\end{array}$ & & & & $\begin{array}{ccc} & \text { (1) } & + \\
\mathrm{CH} & & \text { vol }\end{array}$ \\
\hline Application name & $\begin{array}{l}\text { Pilot T-Cast } \\
\text { Magi Connect } \\
\text { TCL }\end{array}$ & $\begin{array}{l}\text { ZaZa } \\
\text { Remote }\end{array}$ & $\begin{array}{l}\text { Universal } \\
\text { remote } \\
\text { control }\end{array}$ & $\begin{array}{l}\text { MI remote } \\
\text { Controller }\end{array}$ & $\begin{array}{l}\text { Universal } \\
\text { remote } \\
\text { control - Lean } \\
\text { remote }\end{array}$ & $\begin{array}{l}\text { Smart TV } \\
\text { remote for all }\end{array}$ \\
\hline Updates & 1 & 2 & 3 & 4 & 5 & 2 \\
\hline Interaction with the user & 2 & 1 & 4 & 3 & 0 & 4 \\
\hline $\begin{array}{l}\text { Support for more than one brand } \\
\text { of receiver }\end{array}$ & 0 & 4 & 3 & 0 & 4 & 4 \\
\hline Support for additional devices & 0 & 3 & 3 & 4 & 4 & 2 \\
\hline $\begin{array}{l}\text { Possibility to buy a premium } \\
\text { application }\end{array}$ & 5 & 5 & 3 & 0 & 5 & 4 \\
\hline $\begin{array}{l}\text { Possibility to buy individual } \\
\text { functions }\end{array}$ & 2 & 4 & 1 & 0 & 4 & 3 \\
\hline Infrared communication & 0 & 0 & 0 & 5 & 0 & 5 \\
\hline Bluetooth communication & 5 & 5 & 5 & 5 & 5 & 5 \\
\hline Wi-Fi communication & 5 & 5 & 5 & 5 & 5 & 5 \\
\hline Configurable remote control & 2 & 4 & 5 & 4 & 4 & 3 \\
\hline Number of available languages & 4 & 5 & 4 & 5 & 4 & 2 \\
\hline Ability to stream & 3 & 3 & 4 & 4 & 5 & 0 \\
\hline $\begin{array}{l}\text { Supports more than one device } \\
\text { at a time }\end{array}$ & 0 & 0 & 0 & 5 & 0 & 1 \\
\hline Dedicated to one brand only & 5 & 0 & 0 & 0 & 0 & 0 \\
\hline Interface configuration & 1 & 4 & 3 & 4 & 4 & 2 \\
\hline Easy to use & 3 & 4 & 2 & 4 & 4 & 2 \\
\hline Total & 38 & 49 & 45 & 52 & 53 & 44 \\
\hline
\end{tabular}


Table 1. Cont.

\begin{tabular}{|c|c|c|c|c|c|c|}
\hline No. & 13 & 14 & 15 & 16 & 17 & 18 \\
\hline Logo/Thumbnail & 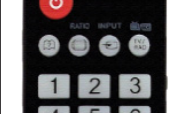 & & की 10 & & LG & 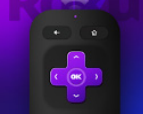 \\
\hline Application name & $\begin{array}{l}\text { TV remote for } \\
\text { LG web OS } \\
\text { Smart TV }\end{array}$ & $\begin{array}{l}\text { TV remote } \\
\text { for LG }\end{array}$ & $\begin{array}{l}\text { Technika TV } \\
\text { remote }\end{array}$ & $\begin{array}{c}\text { Roku remote: } \\
\text { RoSpikes } \\
\text { (WiFi+IR) }\end{array}$ & $\begin{array}{l}\text { Universal } \\
\text { LG remote } \\
\text { control for } \\
\text { Smart TV }\end{array}$ & $\begin{array}{l}\text { TV remote } \\
\text { Roku free }\end{array}$ \\
\hline Updates & 2 & 3 & 4 & 5 & 3 & 5 \\
\hline Interaction with the user & 3 & 1 & 2 & 3 & 4 & 1 \\
\hline $\begin{array}{l}\text { Support for more than one } \\
\text { brand of receiver }\end{array}$ & 5 & 0 & 4 & 2 & 0 & 4 \\
\hline Support for additional devices & 0 & 0 & 2 & 0 & 5 & 0 \\
\hline $\begin{array}{l}\text { Possibility to buy a premium } \\
\text { application }\end{array}$ & 0 & 0 & 0 & 0 & 5 & 4 \\
\hline $\begin{array}{l}\text { Possibility to buy individual } \\
\text { functions }\end{array}$ & 3 & 0 & 0 & 2 & 3 & 3 \\
\hline Infrared communication & 0 & 5 & 5 & 5 & 0 & 5 \\
\hline Bluetooth communication & 5 & 5 & 5 & 0 & 0 & 0 \\
\hline Wi-Fi communication & 5 & 5 & 5 & 5 & 5 & 5 \\
\hline Configurable remote control & 3 & 3 & 2 & 3 & 5 & 2 \\
\hline Number of available languages & 2 & 5 & 5 & 2 & 5 & 3 \\
\hline Ability to stream & 0 & 2 & 3 & 0 & 5 & 1 \\
\hline $\begin{array}{l}\text { Supports more than one device } \\
\text { at a time }\end{array}$ & 0 & 0 & 0 & 0 & 0 & 0 \\
\hline Dedicated to one brand only & 0 & 3 & 4 & 5 & 0 & 3 \\
\hline Interface configuration & 3 & 2 & 4 & 3 & 5 & 2 \\
\hline Easy to use & 4 & 1 & 2 & 1 & 1 & 2 \\
\hline Total & 35 & 35 & 47 & 36 & 46 & 40 \\
\hline
\end{tabular}

\begin{tabular}{|l|c|c|c|c|c|c|}
\hline \multicolumn{1}{|c|}{ No. } & 19 & 20 & 21 & 22 & 23 \\
\hline Logo/Thumbnail & RokU & & & & \\
\hline Application name & $\begin{array}{c}\text { Roku - official } \\
\text { Remote } \\
\text { Control }\end{array}$ & mi BOX & $\begin{array}{c}\text { Smart TV } \\
\text { Sony TV }\end{array}$ & $\begin{array}{c}\text { TV remote } \\
\text { smart TV }\end{array}$ & $\begin{array}{c}\text { Android TV } \\
\text { Remote } \\
\text { Control }\end{array}$ & $\begin{array}{c}\text { Philips TV } \\
\text { remote }\end{array}$ \\
\hline Updates & 3 & 1 & 2 & 3 & 2 & 1 \\
\hline Interaction with the user & 2 & 1 & 4 & 3 & 0 & 4 \\
\hline $\begin{array}{l}\text { Support for more than one brand } \\
\text { of receiver }\end{array}$ & 3 & 5 & 0 & 2 & 3 & 3 \\
\hline Support for additional devices & 0 & 3 & 3 & 4 & 4 & 2 \\
\hline $\begin{array}{l}\text { Possibility to buy a premium } \\
\text { application }\end{array}$ & 5 & 5 & 3 & 0 & 5 & 4 \\
\hline $\begin{array}{l}\text { Possibility to buy individual } \\
\text { functions }\end{array}$ & 2 & 4 & 1 & 0 & 4 & 3 \\
\hline Infrared communication & 0 & 0 & 5 & 5 & 0 & 5 \\
\hline Bluetooth communication & 5 & 5 & 5 & 5 & 5 & 5 \\
\hline Wi-Fi communication & 5 & 0 & 0 & 5 & 5 & 5 \\
\hline Configurable remote control & 2 & 4 & 5 & 4 & 4 & 3 \\
\hline Number of available languages & 4 & 5 & 4 & 5 & 4 & 2 \\
\hline Ability to stream & 3 & 3 & 4 & 4 & 5 & 0 \\
\hline $\begin{array}{l}\text { Supports more than one device } \\
\text { at a time }\end{array}$ & 0 & 0 & 0 & 5 & 0 & 1 \\
\hline Dedicated to one brand only & 5 & 0 & 0 & 0 & 0 & 0 \\
\hline Interface configuration & 1 & 4 & 3 & 4 & 4 & 2 \\
\hline Easy to use & 3 & 5 & 2 & 4 & 3 & 4 \\
\hline Total & 45 & 41 & 53 & 48 & 44 \\
\hline
\end{tabular}


Table 1. Cont.

\begin{tabular}{|c|c|c|c|c|c|c|}
\hline No. & 25 & 26 & 27 & 28 & 29 & 30 \\
\hline Logo/Thumbnail & & & & & $\mathrm{OK}$ & \\
\hline Application name & $\begin{array}{l}\text { CetusPlay } \\
\text { android TV } \\
\text { box }\end{array}$ & $\begin{array}{l}\text { Remote for } \\
\text { Panasonic } \\
\text { smart TV }\end{array}$ & Yatse Kodi & $\begin{array}{c}\text { Remote } \\
\text { control for } \\
\text { Philips Smart } \\
\text { TV }\end{array}$ & $\begin{array}{l}\text { Toshiba } \\
\text { TV remote } \\
\text { control }\end{array}$ & $\begin{array}{c}\text { Remote for } \\
\text { TCL - Roku } \\
\text { TV }\end{array}$ \\
\hline Updates & 2 & 3 & 1 & 5 & 1 & 4 \\
\hline Interaction with the user & 0 & 2 & 0 & 3 & 4 & 1 \\
\hline $\begin{array}{l}\text { Support for more than one brand } \\
\text { of receiver }\end{array}$ & 5 & 0 & 5 & 0 & 0 & 0 \\
\hline Support for additional devices & 3 & 0 & 4 & 0 & 3 & 0 \\
\hline $\begin{array}{l}\text { Possibility to buy a premium } \\
\text { application }\end{array}$ & 5 & 3 & 4 & 2 & 3 & 1 \\
\hline $\begin{array}{l}\text { Possibility to buy individual } \\
\text { functions }\end{array}$ & 3 & 2 & 1 & 3 & 4 & 2 \\
\hline Infrared communication & 5 & 0 & 5 & 0 & 0 & 0 \\
\hline Bluetooth communication & 5 & 5 & 5 & 5 & 5 & 5 \\
\hline Wi-Fi communication & 5 & 0 & 5 & 5 & 5 & 0 \\
\hline Configurable remote control & 5 & 2 & 4 & 4 & 3 & 2 \\
\hline Number of available languages & 4 & 3 & 4 & 3 & 4 & 4 \\
\hline Ability to stream & 5 & 0 & 2 & 3 & 0 & 0 \\
\hline $\begin{array}{l}\text { Supports more than one device } \\
\text { at a time }\end{array}$ & 0 & 0 & 5 & 0 & 0 & 0 \\
\hline Dedicated to one brand only & 0 & 5 & 0 & 5 & 5 & 5 \\
\hline Interface configuration & 2 & 3 & 4 & 3 & 5 & 1 \\
\hline Easy to use & 1 & 5 & 2 & 1 & 3 & 4 \\
\hline Total & 50 & 33 & 51 & 42 & 45 & 29 \\
\hline
\end{tabular}

\begin{tabular}{|c|c|c|c|c|c|c|}
\hline No. & 31 & 32 & 33 & 34 & 35 & 36 \\
\hline Logo/Thumbnail & $\langle\circ\rangle$ & & (1) : 8 & & & \\
\hline Application name & $\begin{array}{l}\text { Rokie - } \\
\text { Remote for } \\
\text { Roku }\end{array}$ & $\begin{array}{l}\text { Sharp smart } \\
\text { TV remote }\end{array}$ & $\begin{array}{c}\text { Ematic } \\
\text { JetStream } \\
\text { TV remote }\end{array}$ & $\begin{array}{c}\text { Remote } \\
\text { control for } \\
\text { android TV }\end{array}$ & $\begin{array}{c}\text { Remote for } \\
\text { Hisense } \\
\text { Roku TV }\end{array}$ & $\begin{array}{l}\text { Universal } \\
\text { Remote for } \\
\text { All TV }\end{array}$ \\
\hline Updates & 2 & 2 & 4 & 3 & 2 & 5 \\
\hline Interaction with the user & 0 & 2 & 3 & 1 & 0 & 1 \\
\hline $\begin{array}{l}\text { Support for more than one brand } \\
\text { of receiver }\end{array}$ & 3 & 0 & 0 & 4 & 0 & 4 \\
\hline Support for additional devices & 0 & 0 & 0 & 3 & 0 & 2 \\
\hline $\begin{array}{l}\text { Possibility to buy a premium } \\
\text { application }\end{array}$ & 0 & 3 & 2 & 5 & 3 & 4 \\
\hline $\begin{array}{l}\text { Possibility to buy individual } \\
\text { functions }\end{array}$ & 3 & 4 & 3 & 1 & 3 & 1 \\
\hline Infrared communication & 0 & 5 & 5 & 0 & 5 & 0 \\
\hline Bluetooth communication & 5 & 5 & 5 & 5 & 5 & 5 \\
\hline Wi-Fi communication & 5 & 0 & 0 & 5 & 0 & 5 \\
\hline Configurable remote control & 2 & 1 & 4 & 3 & 4 & 1 \\
\hline Number of available languages & 4 & 3 & 3 & 2 & 2 & 3 \\
\hline Ability to stream & 2 & 0 & 3 & 4 & 4 & 4 \\
\hline $\begin{array}{l}\text { Supports more than one device } \\
\text { at a time }\end{array}$ & 0 & 0 & 0 & 0 & 0 & 0 \\
\hline Dedicated to one brand only & 0 & 5 & 5 & 0 & 5 & 0 \\
\hline Interface configuration & 0 & 2 & 1 & 3 & 1 & 3 \\
\hline Easy to use & 3 & 4 & 5 & 5 & 1 & 5 \\
\hline Total & 29 & 36 & 43 & 44 & 35 & 43 \\
\hline
\end{tabular}


Table 1. Cont.

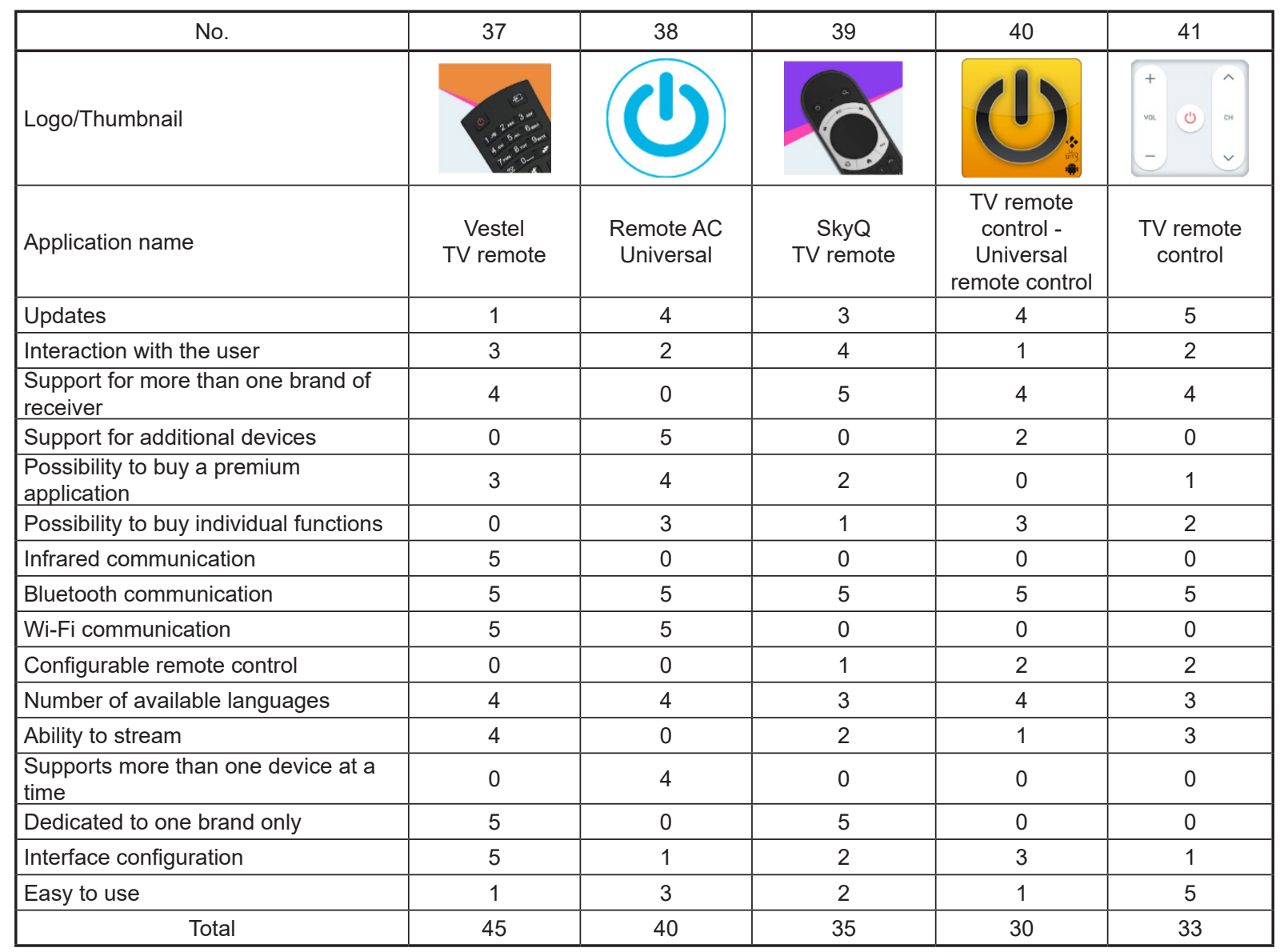

which it is able to connect and a large number of available functions that the user can adjust to their needs. During tests of work with various models of receivers, the application connects seamlessly, however, receiver auto-detection and automatic configuration did not work properly every time. Configuration of the application is at a very high level, with easy addition of custom shortcuts or easy and intuitive programming of your own buttons, which is missing in competing applications. A plus is the attention to detail such as customizing the theme of the app in different colors, good interaction with app users in comments, listening to suggestions and making changes. Also an advantage is the ability to control the TV using different data transmission channels: infrared diode, Wi-Fi and Bluetooth so the user can choose the most suitable way to control the receiver. The disadvantage is the inability to purchase individual functions individually in the premium paid version. This application scored the most points in the analysis process. The second type are free applications that are simple to use and do not have additional or complicated functions. They are dedicated for given models and brands and in most cases the receiver's auto-detection works correctly and does not cause any problems when searching and connecting to the TV. The proposed applications are easy to use and will not cause difficulties for people beginning their adventure with this type of software. The list of leading brands of manufacturers and applications, free and paid, are presented in Table 2.

As we note from Table 2, the premium version of the Universal TV remote control application works well for controlling TV sets of leading brands. However, its price fluctuates around US\$11 in the English language version. As far as free applications are concerned, we should recommend applications provided by individual manufacturers, which, however, are not free of imperfections, presented in Table 2, column "Free application".

\section{CONCLUSIONS}

In this article, we explore the problems and challenges that are associated with controlling a smart TV through external apps available on 
Table 2. Comparison of recommended applications by leading TV manufacturers

\begin{tabular}{|c|l|l|}
\hline TV producer & \multicolumn{1}{|c|}{ Paid application } & \multicolumn{1}{c|}{ Free application } \\
\hline LG & Universal TV remote control (premium) & Universal LG remote control for smart TV \\
\hline Samsung & Universal TV remote control (premium) & Samsung smart TV remote control \\
\hline Sony & Universal TV remote control (premium) & Smart TV remote for Sony \\
\hline Philips & Universal TV remote control (premium) & Philips TV remote \\
\hline Panasonic & Universal TV remote control (premium) & Remote for Panasonic smart TV \\
\hline Sharp & Universal TV remote control (premium) & Sharp smart TV remote \\
\hline Toshiba & Universal TV remote control (premium) & Toshiba remote control TV \\
\hline Xiaomi & Universal TV remote control (premium) & Mi remote controller \\
\hline
\end{tabular}

smartphones. The TV's unique combination of processing and connectivity makes it the primary choice for home entertainment. Smart TV manufacturers are producing feature-rich smart TV's. A lot of attention is paid to interactivity and personalization and thus control plays a key role in the entertainment process. Controlling by a smartphone which has become a universal tool allows you to expand the capabilities of your TV. The life cycle of a smart TV is much longer than that of a smartphone or a computer, which makes it difficult to make a purchase decision. When discussing the smart TV interface, it is important to keep in mind the problems of content overload and cognitive overload. In the hardware enrichment race, maintaining the smart $\mathrm{TV}$ as an information carrier is quite a challenge for programmers, software engineers, and designers. This challenge requires careful study so as to maintain the user interface of smart TV as non-technical and interactive, easily controllable in a simple way.

\section{REFERENCES}

1. Alam, I., Khusro, S., Naeem, M., 2017. A review of smart TV: past, present, and future. In: Proc. ICOSST. IEEE, pp. 35-41. https://doi.org/10.1109/ ICOSST.2017.8279002

2. Chorianopoulos, K., 2008. User interface design principles for interactive television applications. Int. J. Hum. Comput. Interact. 24, 556-573. https:// doi.org/10.1080/10447310802205750
3. Frost \& Sullivan Inc., 2018. Global Smart TVs Market, Forecast to 2023 - Research and Markets. https://www.researchandmarkets.com/research/vhww5k/global_smart_tvs?w=12

4. Goodwin, N.C., 1987. Functionality and usability. Commun. ACM 30, 229-233. https://doi. org/10.1145/214748.214758

5. Hess, J., Ley, B., Ogonowski, C., Wan, L., Wulf, V., 2012. Understanding and supporting cross-platform usage in the living room. Entertain. Comput. 3, 3747. https://doi.org/10.1016/j.entcom.2012.04.001

6. Lin, H.X., Choong, Y.-Y., Salvendy, G., 1997. A proposed index of usability: a method for comparing the relative usability of different software systems. Behav. Inf. Technol. 16 (4-5), 267-277. https://doi.org/10.1080/014492997119833

7. Roto, V., Obrist, M., Väänänen-Vainio-Mattila, K., 2009. User experience evaluation methods in academic and industrial contexts. In: Proc. UXEM, doi:10.1.1.150.1764

8. Shokrpour, A., Darnell, M.J., 2017. How people multitask while watching TV. In: Proc. TVX'17, pp. 11-19. https://doi.org/10.1145/3077548.3077558

9. Slot, M., 2007. Changing user roles in ICT developments; the case of digital television. Telemat. Inform. 24, 303-314. https://doi.org/10.1016/j. tele.2007.01.003

10. Tanabian, S., Tanabian, M., 2013. Optimizing usability on video streaming devices and smart TV's. Commun. Comput. Inf. Sci. 373, 164-168. https:// doi.org/10.1007/978-3-642-39473-7_34

11. Vinayagamoorthy, V., Allen, P., Hammond, M., Evans, M., 2012. Researching the user experience for connected TV. In: Proc. CHI EA '12, pp. 589-604. https://doi.org/10.1145/2212776.2212832 